\title{
The Emergence of Gender Segregation: Towards an Integrative Perspective
}

S. Barbu, G. Le Maner-Idrissi and A. Jouanjean

\section{(2) OpenEdition \\ 12 Journals}

\section{Electronic version}

URL: http://journals.openedition.org/cpl/128

DOI: $10.4000 / \mathrm{cpl} .128$

ISSN: $1379-6100$

\section{Publisher}

Centre PsyCLÉ

\section{Printed version}

Date of publication: 1 December 2000

\section{Electronic reference}

S. Barbu, G. Le Maner-Idrissi and A. Jouanjean, «The Emergence of Gender Segregation: Towards an Integrative Perspective », Current psychology letters [Online], 2000/3, 3 | 2000, Online since 04 September 2003, connection on 08 September 2020. URL : http://journals.openedition.org/cpl/128 ; DOI : https://doi.org/10.4000/cpl.128

This text was automatically generated on 8 September 2020

(c) All rights reserved 
The Emergence of Gender Segregation: Towards an Integrative Perspective

S. Barbu, G. Le Maner-Idrissi and A. Jouanjean 